\title{
INFLUENCE OF SYSTEMIC DISEASES ALPHA AND REMOVABLE ORTHODONTIC APPLIANCES ON THE QUALITY OF SALIVA IN CHILDHOOD
}

\author{
Maya Rashkova \\ Department of Children's dental medicine, Faculty of Dental medicine, Medical \\ University, Sofia, Bulgaria
}

\begin{abstract}
During the last 10 years numerous investigations using saliva as a diagnostic tool have been carried out.

The aim of present study is to evaluate saliva qualities for various general diseases and conditions that influence its qualities. (1) Evaluation of salivary flow and saliva consistency of children. (2) Evaluation of saliva $\mathrm{pH}$ and buffer capacity of children.

Material and Methods. The investigation was carried out with 126 children (age 6 to 17) selected by their general diseases and conditions influencing the oral risk environment. The children were divided into 4 groups: 30 children with diabetes, 25 children with asthma treated with local corticosteroids, 27 healthy children with orthodontic treatment, 34 children as a control group (healthy children). The saliva of the children was tested with the help of "Saliva Check" of GC Company. The instructions of the company producer were followed.

Results. Stimulated saliva current is reliably lower for children with asthma treated with local corticosteroids, diabetes and children with orthodontic appliances. Saliva $\mathrm{pH}$ is with lower values for children with diabetes and asthma diseases predisposing to acid oral environment. The decreased saliva buffer capacity for children with diabetes and asthma is an indicator for the difficult regulation of the dynamically changing oral electrolytic balance of those children.

Conclusion. The saliva parameters studied can be used as biomarkers of the liquid oral environment with regard to the risks for caries and periodontal diseases in children. General health status influences saliva qualities increasing thus indirectly the caries risk.
\end{abstract}

Key Words: salivary flow, saliva $\mathrm{pH}$, buffer capacity, diabetes, asthma, local corticosteroids, healthy children, orthodontic treatment,

\section{INTRODUCTION}

During the last 10 years numerous investigations using saliva as a diagnostic tool have been carried out $(1,2,3)$. Saliva role in the development of oral diseases is primarily protective. Saliva is a source of the basic substances building tooth pellicle. It realizes mouth cleaning from sugars and acids and maintains the mineral homeostasis along the enamel surface. Due to its concentration with mineral ions, important for the enamel, saliva contains buffers maintaining oral environment at about neutral $\mathrm{pH}$. Saliva directly opposes caries genetic situation in the dental biofilm and influences the formation of subgingival biofilm associated with periodontal diseases. The presence of various antibacterial factors (enzymes, antibodies, etc.) in the saliva, its role as a lubricant (moistener) as well as its participation during the initial stage of digestion, define the liquid oral environment as the most important factor for maintaining oral homeostasis. And this in itself is a necessary condition for oral health oral environment without active oral pathology $(4,5,6,7)$.

All this requires that the study of saliva qualities become a part of the evaluation of the oral risk environment. Simplified tests for such evaluations have been developed allowing the follow up of some of the parameters characterizing the physicochemical properties of saliva.

The aim of present study is to evaluate saliva qualities for various general diseases and conditions that influence its qualities.

Tasks:

1. Evaluation of salivary flow and saliva consistency of children.

2. Evaluation of saliva $\mathrm{pH}$ and buffer capacity of children.

\section{MATERIAL AND METHODS}

\section{Object of the Study}

The investigation was carried out with 126 children (age 6 to 17) selected by their general diseases and conditions influencing the oral risk environment. The children were divided into 4 groups:

- $1^{\text {st }}$ group - 30 children with diabetes (from the Clinic of Endocrinology, Diabetes and Genetics, Medical University, Sofia). Children with non-controlled diabetes were selected. The following parameters of diabetes development were registered:

- duration of the disease minimum 2 years;

- laboratory parameters characterizing the diabetes at 
the time of our study. According to these characteristics, children were placed in the group of children with noncontrolled diabetes at the time of the study.

- $2^{\text {nd }}$ group - 25 children with asthma treated with local corticosteroids (from the Clinic on Child Pulmonary Diseases, Medical University, Sofia).

- The children with asthma were selected by the following criteria:

- diagnosis - atopical asthma;

- degree of the disease - average heavy form;

- duration of the disease -minimum 2 years;

- treatment with corticosteroids - at the moment and not less than 6 months before;

- type of local corticosteroid - Flixotide. children);

- 3rd group - 34 children as a control group (healthy

- $4^{\text {th }}$ group -27 healthy children with orthodontic treatment (removable orthodontic appliances) for minimum of 2 years.

\section{Saliva study}

The saliva of the children was tested with the help of "Saliva Check" of GC company. The instructions of the company producer were followed.

3. Statistical processing with the help of computer program SPSS-15. The following were used: nonparametric analysis $\left(\chi^{2}\right)$, independent Samples T-Test.

\section{RESULTS}

\section{Evaluation of stimulated saliva current for} children studied

The children, grouped in the 4-rate scale described above, were evaluated according to the rate of the stimulated saliva current. The results obtained are shown in Fig. 1.

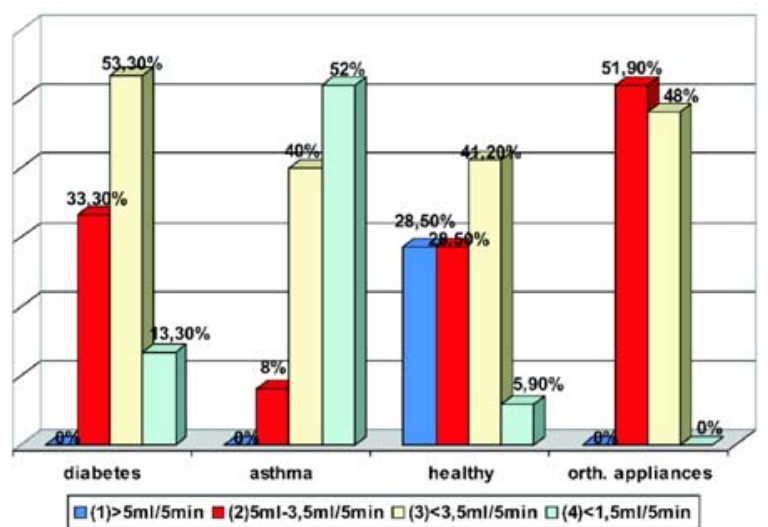

Fig. 1. Rate of the stimulated saliva current for the four groups of children

Only $\mathrm{j}$ of the healthy children fall into the limits of the norm ( $>5 \mathrm{ml} / 5 \mathrm{~min})$ according to the company producer of the test. Very weak saliva current $(<1,5 \mathrm{ml} / 5 \mathrm{~min})$ was observed in $13,3 \%$ of the children with diabetes and $\mathrm{S}$ of the children with asthma treated for a long time with local inhaler corticosteroid medications. The rest of the children exhibit saliva current between $5 \mathrm{ml} / 5 \mathrm{~min}$ and $1,5 \mathrm{ml} / 5 \mathrm{~min}$.

Taking into consideration the fact that literature accepts, for children, as a norm the rate 0,7 to $1,0 \mathrm{ml} / \mathrm{min}$ $(3,5 \mathrm{ml}-5,0 \mathrm{ml} / 5 \mathrm{~min})$ of the stimulated saliva current, we divided the children additionally into two groups: (1) with saliva current $-3,5-5 \mathrm{ml} / 5 \mathrm{~min}$. and (2) with decreased saliva current $-<3,5 \mathrm{ml} / 5 \mathrm{~min}$. The results obtained are shown in the table below.

Table 1. Rate of the stimulated saliva current in children

\begin{tabular}{|c|c|c|c|c|c|c|c|c|c|c|}
\hline \multirow[t]{2}{*}{$\begin{array}{l}\text { Salivary current } \\
(\mathrm{ml} / 5 \mathrm{~min} .)\end{array}$} & \multicolumn{2}{|c|}{$\begin{array}{l}\text { (1) with } \\
\text { diabetes }\end{array}$} & \multicolumn{2}{|c|}{$\begin{array}{l}\text { (2) with } \\
\text { asthma* }\end{array}$} & \multicolumn{2}{|c|}{$\begin{array}{l}\text { (3) healthy } \\
\text { children }\end{array}$} & \multicolumn{2}{|c|}{$\begin{array}{c}\text { (4) with } \\
\text { removable } \\
\text { orth.appliances }\end{array}$} & \multicolumn{2}{|c|}{ total } \\
\hline & $\mathrm{n}$ & $\%$ & $\mathrm{n}$ & $\%$ & $\mathrm{n}$ & $\%$ & $\mathrm{n}$ & $\%$ & $\mathrm{n}$ & $\%$ \\
\hline $\begin{array}{l}\text { Normal salivary } \\
\text { current } \\
(3,5-5 \mathrm{ml} / 5 \mathrm{~min} .)\end{array}$ & 10 & 33,3 & 2 & 8,0 & 18 & 52,9 & 14 & 51,9 & 44 & 37,17 \\
\hline $\begin{array}{l}\text { Low salivary } \\
\text { current } \\
(<3,5 \mathrm{ml} / 5 \mathrm{~min} .)\end{array}$ & 20 & 66,6 & 23 & 92,0 & 16 & 47,1 & 13 & 48,1 & 72 & 62,05 \\
\hline Total & 30 & 100 & 25 & 100 & 34 & 100 & 27 & 100 & 116 & 100 \\
\hline$\chi^{2}$ & & $1,3=2$ & $\mathrm{P}>0$ & & $=12$ & $\mathrm{P}<0$ & & $23,4=$ & $\overline{\mathrm{P}>}$ & \\
\hline
\end{tabular}

The results show that $\mathrm{S}$ of the healthy children as well as the healthy children with orthodontic appliances have saliva current of $0,70-1,0 \mathrm{ml} / \mathrm{min}$. Decreased saliva current is found in $2 / 3$ of the children with diabetes and in much higher percent of the children with asthma (92\%) treated with local corticosteroids. Statistically reliable difference $(\mathrm{P}<0,0001)$ is observed between healthy children and children with asthma. 


\section{Evaluation of saliva consistency}

The distribution of the children according to their saliva consistency is shown in the next table.

Table 2. Saliva consistency of the children studied

\begin{tabular}{|c|c|c|c|c|c|c|c|c|c|c|}
\hline \multirow{2}{*}{$\begin{array}{l}\text { Saliva } \\
\text { consistency }\end{array}$} & \multicolumn{2}{|c|}{$\begin{array}{l}\text { (1) with } \\
\text { diabetes }\end{array}$} & \multicolumn{2}{|c|}{$\begin{array}{l}\text { (2) with } \\
\text { asthma }\end{array}$} & \multicolumn{2}{|c|}{$\begin{array}{l}\text { (3) healthy } \\
\text { children }\end{array}$} & \multicolumn{2}{|c|}{$\begin{array}{l}\text { (4) orth. } \\
\text { appliances }\end{array}$} & \multicolumn{2}{|c|}{ total } \\
\hline & $\mathrm{n}$ & $\%$ & $\mathrm{n}$ & $\%$ & $\mathrm{n}$ & $\%$ & $\mathrm{n}$ & $\%$ & $\mathrm{n}$ & $\%$ \\
\hline liquid saliva & 11 & 40 & 12 & 48 & 7 & 20,6 & 8 & 29,6 & 38 & 32,75 \\
\hline Saliva Bubble & 12 & 36,7 & 11 & 44 & 21 & 61,8 & 18 & 66,7 & 72 & 62,06 \\
\hline viscous saliva & 7 & 23,3 & 2 & 8 & 6 & 17,6 & 1 & 3,7 & 16 & 13,79 \\
\hline total & 30 & 100 & 25 & 100 & 34 & 100 & 27 & 100 & 116 & 100 \\
\hline$\chi^{2}$ & & $=0,31$ & $, 05)$ & & $3=1$, & $(\mathrm{P}>0$ & & $\chi 23$, & 838 & $0,05)$ \\
\hline
\end{tabular}

The results show that saliva consistency does not differ for the 4 groups of children studied. Most often viscous saliva is observed in children with diabetes $(23,5 \%)$, and that percentage drops to $17,6 \%$ for healthy children however there is statistical reliability $(\mathrm{P}>0,05)$. An interesting fact is that only $20,6 \%$ of the healthy children have liquid saliva while $61,8 \%$ have bubble type saliva.

\section{Evaluation of saliva $\mathrm{pH}$ for children studied}

Saliva $\mathrm{pH}$ is one of the main indicators in evaluating risk oral environment for caries. Saliva changes constantly its $\mathrm{pH}$, most often in connection with feeding. Regulation is performed by the three types of buffer systems and $\mathrm{pH}$ is maintained within the limits of 6,8-7.2 or around neutral.

Table 3. $\mathrm{pH}$ of saliva for the children in the four groups

\begin{tabular}{|l|l|l|l|l|}
\hline Children & $\mathrm{n}$ & mean & $\pm \mathrm{SD}$ & $\mathrm{SE}$ \\
\hline (1) with diabetes & 30 & 6,46 & $\pm 0,526$ & 0,096 \\
\hline (2) with asthma & 25 & 6,44 & $\pm 0,574$ & 0,114 \\
\hline (3) healthy children & 34 & 6,97 & $\pm 0,281$ & 0,048 \\
\hline (4) with orth.appliances & 27 & 6,76 & $\pm 0,288$ & 0,055 \\
\hline
\end{tabular}

The average $\mathrm{pH}$ values of the children studied shows that healthy children and children with orthodontic appliances are within the norms. Children with diabetes and those with asthma have decreased $\mathrm{pH}(\mathrm{P}<0,05)$, average $\mathrm{pH}$ 6,45 and 6,44 correspondingly. studied.

4. Evaluation of saliva buffer capacity of children

Buffer capacity is the next marker for stable liquid oral environment since it shows the ability of the environment to maintain the electrolytic balance within neutral $\mathrm{pH}(6,8-7,2)$. According to the rates of evaluation of the buffer capacity provided by the company producer of the test, all children studied have weaker than the normal buffer capacity.

Table 4. Buffer capacity of the saliva of children studied

\begin{tabular}{|c|c|c|c|c|c|c|c|c|c|c|}
\hline \multirow[t]{2}{*}{ buffer capacity } & \multicolumn{2}{|c|}{$\begin{array}{l}\text { (1) with } \\
\text { diabetes }\end{array}$} & \multicolumn{2}{|c|}{$\begin{array}{l}\text { (2) with } \\
\text { asthma }\end{array}$} & \multicolumn{2}{|c|}{$\begin{array}{l}\text { (3) healthy } \\
\text { children }\end{array}$} & \multicolumn{2}{|c|}{$\begin{array}{l}\text { (4)orth. } \\
\text { appliances }\end{array}$} & \multicolumn{2}{|c|}{ total } \\
\hline & $\mathrm{n}$ & $\%$ & $\mathrm{n}$ & $\%$ & $\mathrm{n}$ & $\%$ & $n$ & $\%$ & $\mathrm{n}$ & $\%$ \\
\hline $\begin{array}{l}\text { Normal } \\
10-12 \text { points }\end{array}$ & 5 & 16,7 & 0 & 0 & 13 & 38,2 & 3 & 11,1 & 21 & 18,10 \\
\hline Low $<10$ points & 25 & 83,3 & 25 & 100 & 21 & 61,7 & 24 & 88,9 & 95 & 81,90 \\
\hline total & 30 & 100 & 25 & 100 & 34 & 100 & 27 & 100 & 116 & 100 \\
\hline$\chi^{2}$ & \multicolumn{4}{|c|}{$\chi 2 \quad 1,3=3,66 \quad P<0,05$} & $3=12$ & $\mathrm{P}<0$ & & \multicolumn{3}{|c|}{$\chi 2_{3,4}=16,9 \quad \mathrm{P}<0,05$} \\
\hline
\end{tabular}


The children with normal buffer capacity are more in the group of healthy children $-38,2 \%$ compared to the rest of the groups. More than $2 / 3$ of the children with diabetes have decreased buffer capacity. Similar results are observed for the children with orthodontic appliances. All children with asthma also have decreased buffer capacity. Of all the children with decreased buffer capacity, for approximately $2 / 3$ the decrease is slight, and only for a small part the decrease is stronger.

\section{DISCUSSION}

The complex interactions between biofilm, saliva, and teeth enamel represent the basis of the initiation of caries lesions as well as of their treatment. They are influenced by the rate of saliva current. Our investigations show that saliva current in childhood if decreased compared to the average values of adults and that certain diseases as diabetes, asthma, and prolonged action of local corticosteroids on the oral environment lead to a decrease of saliva current. In this way the risk oral environment undergoes changes to an increase of the risk of plaque dependent diseases such as caries and periodontal diseases in childhood.

Literature accepts values of $0,7-1,0 \mathrm{ml} / \mathrm{min}$ as an average rate of saliva current $(8,9,10)$. According to the company producer of the test "Saliva Check" used by us, $0,7 \mathrm{ml} / \mathrm{min}$ is a weal saliva current. There are no average values for stimulated saliva current found to vary within greater limits for children. Childhood explains the distraction experienced when collecting saliva which is an additional factor for that type of evaluation. The conclusion that can be drawn from our study is that $0,7-1,0 \mathrm{ml} / \mathrm{min}$ may be accepted as an average value of stimulated saliva current in childhood. Below this value, the weak saliva current transforms from protective to a risk factor for the formation of biofilm and development of caries and periodontal diseases. In such cases a preventive program including measures for saliva stimulation (xylitol chewing gums, certain foods, artificial saliva, medicines stimulating saliva secretion, etc.) is mandatory. The strongly decreased saliva current for children with asthma compared to healthy children is a further proof of the increased oral risk for children treated with local corticosteroid medications.

Saliva viscosity due to mucin is better expressed in children with diabetes for whom a higher quantity of saliva glucose is recorded. It could be a substrate for the formation of more mucin. Increased saliva viscosity is also a risk factor for biofilm formation since viscous saliva has slower cleaning action.
The conclusion that can be made with regard to saliva acidity is that it is more acid for children with diabetes, asthma, and children treated with corticosteroids compared to health children. For children with asthma this is a result of the local action of the corticosteroids.

The results show that $\mathrm{pH}$ may be used as an important marker for risk oral environment especially for children with diseases predisposing to acid environment.

Having in view the dynamically changing oral environment in childhood, the slightly decreased buffer capacity can be accepted as a norm. The test "Saliva Check" does not offer separate values of the different parameters for childhood though children's saliva has its own differences. The comparison with the control group of healthy children shows that the buffer capacity of children with diabetes, asthma, and orthodontic appliances is even weaker. This is yet one more risk factor that influences the regulation of the dynamically changing oral electrolytic balance.

The saliva parameters studied can be used as biomarkers of the liquid oral environment with regard to the risks for caries and periodontal diseases in children. General health status influences saliva qualities increasing thus indirectly the caries risk. The creation and application of different programs for regulation of the oral liquid environment is an important conditions for maintaining oral health especially for children with diseases undergoing treatment that has a mechanism allowing the disease to influence saliva qualities.

The diseases chosen by us are exactly of that kind and the results prove the statement that general health status influences oral environment in particular the qualities of the saliva.

\section{CONCLUSIONS}

1. Stimulated saliva current in children is weaker than that of adults. It is reliably lower for children with asthma treated with local corticosteroids, diabetes and children with orthodontic apparatuses,

2. Saliva consistency does not change for children with diabetes, asthma, and orthodontic apparatuses when compared to healthy children.

3. Saliva $\mathrm{pH}$ is with lower values for children with diabetes and asthma - diseases predisposing to acid environment.

4. The decreased saliva buffer capacity for children with diabetes and asthma is an indicator for the difficult regulation of the dynamically changing oral electrolytic balance of those children.

\section{Acknowledgement}

The research is part of a GRAND project (ref:53/2007), funded by the Medical University of Sofia. 


\section{REFERENCES}

1. Dawes C. Considerations in the Development of Diagnostic Tests on Saliva. Ann NY Acad Sciences. 1993 Sep; 694:265-269. [CrossRef]

2. Dodds MW, Jonson DA, Yeh CK. Health benefits of saliva: a review. $J$ Dent 2005 Mar;33(3):223-233. [PubMed] [CrossRef]

3. Haeckel R, Hдnecke P. Application of saliva, sweat and tear fluid for diagnostic purposes. Ann Biol Clin (Paris). 1993; 51(10-11):903-910. [PubMed]

4. Helmerhorst EJ, Oppenheim FG. Saliva: a Dynamic Proteome J Dent Res.
2007 Aug;86(8):680-693, [PubMed]

5. Lawrence HP. Salivary Markers of Systemic Disease: Noninvasive Diagnosis of Disease and Monitoring of General Health. J Can Dent Assoc. 2002 Mar; 68(3):170-174. [PubMed]

6. Tabak LA. A Revolution in Biomedical Assessment: The Development of Salivary Diagnostics. J Dent Educ. 2001 Dec;65(12):1335-1339. [PubMed]

7. Malamud D. Saliva as a diagnostic fluid. Dent Clin North Am. 2011 Jan; 55(1):159-178. [PubMed]

8. Malamud D. Salivary diagnostics: the future is now. J Am Dent Assoc. 2006 Mar;137(3):284-286. [PubMed]

9. Nauntofte B, Tenevuo JO, Lagerlof F. Secretion and composition of saliva. In: Fejerskov O. and Kidd E, eds. Dental Caries. The disease and its clinical management. Oxford. Blackwell Munksgard. 2003. p. 7-29.

10. Tenovuo J. Salivary parameters of relevance for assessing caries activity in individuals and populations. Community Dent Oral Epidemiol. 1997 Feb;25(1):8286. [PubMed]

\section{Address for correspondence:}

Maya Rashkova, Associate professor, $\mathrm{PhD}$, MD

Department of Children's dental medicine, Faculty of Dental medicine - Sofia 1, St. Georgi Sofiiski str., 1431 Sofia, Bulgaria E-mail: mayarashkova@mail.bg 